\title{
Effect of prognostic classification on temsirolimus efficacy and safety in patients with relapsed or refractory mantle cell lymphoma: a retrospective analysis
}

Georg Hess ${ }^{1 *}$, Bertrand Coiffier ${ }^{2}$, Michael Crump ${ }^{3}$, Christian Gisselbrecht ${ }^{4}$, Fritz Offner ${ }^{5}$, Jorge Romaguera ${ }^{6}$, Lisa Kang ${ }^{7}$ and Pádraig J Moran ${ }^{8}$

\begin{abstract}
Background: Temsirolimus, a selective inhibitor of the mammalian target of rapamycin, has demonstrated clinical benefit versus investigator's choice (INV) of therapy in patients with relapsed/refractory mantle cell lymphoma (MCL).

Methods: This post hoc study retrospectively assigned simplified Mantle Cell Lymphoma International Prognostic Index (MIPI) scores (ie, secondary MIPI) based on parameters at the time of randomization in patients with MCL (N = 162) who received temsirolimus $175 \mathrm{mg}$ once weekly for 3 weeks followed by once-weekly $75 \mathrm{mg}$ or $25 \mathrm{mg}$ or the INV of active therapy. Outcomes were analyzed according to the low-, intermediate- or high-risk category.

Results: Patient distribution by MIPI risk category was 31\%, 39\%, and 30\% in the low-, intermediate-, and high-risk groups, respectively. Among patients in all categories, objective response rate (complete response + partial response) was higher in patients in the temsirolimus 175/75-mg group versus the INV group, respectively: $42 \%$ versus 0\% (low-risk); 33\% versus 5\% (intermediate-risk); 10\% versus 0\% (high-risk). Median progression-free survival was significantly longer with temsirolimus $175 / 75 \mathrm{mg}$ versus INV, respectively, in patients with intermediate (4.3 vs 1.9 months; $P=0.035$ ) or high (4.5 vs 1.6 months; $P=0.0025$ ) risk, and a trend toward improvement was observed in patients with low risk (5.3 vs 2.6 months; $P=0.091$ ). Improvement in median overall survival was observed with temsirolimus $175 / 75$ mg versus INV in low-risk patients (18.0 vs 10.5 months, respectively; $P=0.069$ ).
\end{abstract}

Conclusions: This analysis suggests that, compared with INV, temsirolimus demonstrated benefit in all MIPI risk categories in patients with MCL. In all treatment groups, patients with high secondary MIPI scores at baseline faced a dismal prognosis.

Trial registration: ClinicalTrials.gov NCT00117598.

Keywords: Mantle cell lymphoma, Prognostic, Risk, Temsirolimus, Efficacy, Safety

\section{Introduction}

The introduction of new therapeutic strategies has led to improvements in response rates and/or longer progressionfree survival (PFS) in individuals who are newly diagnosed with mantle cell lymphoma (MCL) [1-4]. However, outcomes remain poor (median survival, $<2$ years) in

\footnotetext{
*Correspondence: georg.hess@unimedizin-mainz.de

1 Department of Hematology/Oncology, Johannes Gutenberg University, Langenbeckstr. 1, Mainz DE 55101, Germany

Full list of author information is available at the end of the article
}

patients with MCL that has relapsed or is refractory to first-line regimens.

Temsirolimus is a selective inhibitor of the mammalian target of rapamycin (mTOR) signaling protein, which can be aberrantly activated in MCL [5-7]. Several clinical studies, including one randomized controlled trial, have demonstrated that temsirolimus has single-agent activity in patients with relapsed or refractory MCL [8-10]. In Europe, temsirolimus is registered for treatment of adults with relapsed or refractory MCL [11]. Consensus guidelines from the European Society for Molecular Oncology 
support the use of temsirolimus in advanced relapses (greater than second line) and especially in relapsed nonfit patients [12].

In the pivotal multicenter, randomized phase III trial [9], 162 patients with relapsed or refractory MCL were randomized to receive temsirolimus $175 \mathrm{mg}$ once weekly for 3 weeks followed by once-weekly doses of either $75 \mathrm{mg}$ (175/75-mg regimen) or $25 \mathrm{mg}$ (175/25-mg regimen), or the investigator's choice (INV) of active therapy. Treatment in the INV arm consisted primarily of singleagent gemcitabine $(42 \%)$ or fludarabine $(27 \%)$, along with a number other single agents. Temsirolimus $175 / 75 \mathrm{mg}$ significantly prolonged median PFS compared with INV (4.8 vs 1.9 months; hazard ratio $[\mathrm{HR}]=0.44 ; P=0.0009$ ) [9]. The lower dose of temsirolimus $(175 / 25 \mathrm{mg})$ also showed longer median PFS (3.4 months) versus INV, but this difference was not significant. Exploratory subgroup analyses revealed no significant differences in PFS benefit based on sex, Karnofsky performance score (KPS) at baseline, stage of disease at diagnosis, bone marrow involvement, number of extranodal sites or number of prior anticancer regimens [9]. Overall survival was longer with temsirolimus $175 / 75 \mathrm{mg}$ than with INV, but this difference was not significant (12.8 vs 9.7 months; $P=$ 0.3519) [9].

Patients in the phase III trial were not assigned a risk category at baseline, owing to the absence of a robust, validated prognostic scoring system for MCL. Since then, the simplified Mantle Cell Lymphoma International Prognostic Index (MIPI) was validated and was shown to have high prognostic significance for newly diagnosed patients, but it is not formally used for patients with relapsed or refractory disease [13-16]. The objectives of the present study were to understand whether certain MIPI risk groups benefit more from treatment with temsirolimus, or if there are patients unlikely to respond to treatment, and to evaluate the potential utility of MIPI in the context of relapsed/refractory MCL. In this study, simplified MIPI criteria were used to retrospectively assign prognostic scores to patients with relapsed/refractory MCL (ie, secondary MIPI) at the time of their trial enrollment, and outcomes were analyzed according to risk category.

\section{Results and discussion Patients}

Baseline characteristics for the patients in the randomized phase III trial are provided in a prior publication [9]. In brief, median age was 67 years (range 39-88), $81 \%$ of patients were male, $85 \%$ had KPS $\geq 80$, and $46 \%$ had bone marrow involvement. The three treatment groups were generally well balanced with respect to baseline characteristics. An exception was that blastoid histology was noted for zero, nine, and four patients in the temsirolimus 175/75-mg, 175/25-mg, and INV groups, respectively. The median number of prior regimens was three in both temsirolimus groups and four in the INV group. Approximately one third of the patients had undergone autologous hematopoietic stem-cell transplantation following high-dose therapy.

All 162 patients were assigned simplified MIPI scores based on baseline characteristics at their time of enrollment. Of the 162 patients, 14 were missing one MIPI value, one patient was missing two MIPI values, and two patients were missing three MIPI values. Patient distribution was relatively even across the low $(\mathrm{n}=51)$, intermediate $(\mathrm{n}=$ $63)$, and high $(\mathrm{n}=48)$ MIPI risk categories (Table 1$)$.

MIPI distributions were comparable, with the exception of a greater proportion of intermediate-risk patients in the temsirolimus 175/75-mg arm than in the temsirolimus 175/25-mg arm (44\% and 33\%, respectively; Table 1). The INV arm had a greater proportion of low-risk patients and a lower proportion of high-risk patients relative to both of temsirolimus treatment arms (Table 1). Of the 13 patients with blastoid variant, nine were classified as high risk $(175 / 25 \mathrm{mg}[\mathrm{n}=7]$ and INV $[\mathrm{n}=2])$ and four were classified as intermediate risk $(175 / 25 \mathrm{mg}[\mathrm{n}=2]$ and INV $[n=2])$.

\section{Treatment response}

Assessment of best response was available for 123 (76\%) patients. Because the distribution of the 39 patients who did not have tumor assessments available was imbalanced across these small subsets, tumor responses are reported for the evaluable population. Among patients in all MIPI categories, objective response rate (complete response $[\mathrm{CR}]+$ partial response $[\mathrm{PR}]$ ) was higher in the temsirolimus 175/75-mg group compared with the INV arm, respectively: $42 \%$ versus $0 \%$ (low risk), $33 \%$ versus $5 \%$ (intermediate risk), and 10\% versus 0\% (high risk). Complete response was achieved in one patient in each of the two treatment groups; both were classified as intermediate MIPI. In the temsirolimus $175 / 25-\mathrm{mg}$ group, no CR was observed and the objective response rate by MIPI category was 15\% (low risk), 7\% (intermediate risk), and $0 \%$ (high risk).

Table 1 Distribution of patients within each treatment arm by simplified MIPI risk category $[13,14]$

\begin{tabular}{llll}
\hline Patients & $\begin{array}{l}\text { Low risk } \\
\mathbf{n}(\%)\end{array}$ & $\begin{array}{l}\text { Intermediate risk } \\
\mathbf{n}(\%)\end{array}$ & $\begin{array}{l}\text { High risk } \\
\mathbf{n}(\%)\end{array}$ \\
\hline All patients ( $=162)$ & $51(31)$ & $63(39)$ & $48(30)$ \\
$\begin{array}{l}\text { Temsirolimus 175/75 mg } \\
(n=54)\end{array}$ & $14(26)$ & $24(44)$ & $16(30)$ \\
$\begin{array}{l}\text { Temsirolimus 175/25 mg } \\
(n=54)\end{array}$ & $15(28)$ & $18(33)$ & $21(39)$ \\
INV therapy ( $n=54)$ & $22(41)$ & $21(39)$ & $11(20)$ \\
\hline
\end{tabular}

MIPI = Mantle Cell Lymphoma International Prognostic Index; $\mathrm{INV}=$ Investigator's choice. 
Stable disease (SD) is not a standard end point in MCL studies; however, patients can be asymptomatic for long periods. Furthermore, because commonly used regimens administered in the INV group achieved almost no objective responses (one CR, no PR) in these heavily pretreated patients, disease stabilization may be even more relevant in this setting. When analyzed by MIPI categories, higher clinical benefit rates (CBRs), calculated here as $\mathrm{CR}+\mathrm{PR}+$ $\mathrm{SD} \geq 8$ weeks, were observed in the temsirolimus $175 / 75$ $\mathrm{mg}$ arm versus the INV arm for patients in all risk groups (Table 2). Among low-risk patients, CBR was 75\%, 77\%, and $36 \%$ with temsirolimus $175 / 75 \mathrm{mg}$, temsirolimus $175 /$ $25 \mathrm{mg}$, and INV, respectively. Intermediate-risk patients had CBRs of $61 \%, 33 \%$, and $40 \%$ in the respective treatment groups. For high-risk patients, CBRs were $80 \%$ and $33 \%$ in the temsirolimus $175 / 75$ and $175 / 25$ arms, respectively, whereas no patient achieved clinical benefit in the INV arm. These results suggest that patients in all secondary MIPI groups may derive some clinical benefit from temsirolimus. In addition, treatment duration was more sustained in patients administered temsirolimus 175/ $75 \mathrm{mg}$ or $175 / 25 \mathrm{mg}$ compared with INV-treated patients in all MIPI risk categories (Table 3). Although there could be different reasons why, in patients with SD, the doctor and/or patient decide to continue temsirolimus therapy, the longer treatment duration observed with temsirolimus may provide an indirect sign of clinical benefit.

\section{Progression-free survival and overall survival}

Temsirolimus 175/75 mg significantly improved PFS versus INV in intermediate-risk $(P=0.035)$ and high-risk $(P=0.0025)$ patients, and a trend toward improvement was observed in low-risk patients (Figure 1; Table 4). In general, median PFS was longer in patients of all risk groups in the temsirolimus 175/75-mg group than for those in the INV group (Table 4). Among low-risk patients in the temsirolimus 175/25-mg group, median

Table 2 Number of evaluable patients (\%) with stable disease or better response* by MIPI risk category $[13,14]$

\begin{tabular}{|c|c|c|c|}
\hline \multirow[b]{2}{*}{ Treatment } & \multicolumn{3}{|l|}{$\mathrm{n} / \mathrm{N}(\%)[\mathrm{n}]$} \\
\hline & Low risk & Intermediate risk & High risk \\
\hline \multirow[t]{2}{*}{ Temsirolimus 175/75 mg } & $9 / 12(75)$ & $11 / 18(61)$ & 8/10 (80) \\
\hline & [5 PR, $4 \mathrm{SD}]$ & [1 CR, 5 PR, 5 SD] & [1 PR, $7 \mathrm{SD}]$ \\
\hline \multirow[t]{2}{*}{ Temsirolimus 175/25 mg } & 10/13 (77) & 5/15 (33) & 5/15 (33) \\
\hline & [2 PR, $8 \mathrm{SD}]$ & [1 PR, 4 SD] & [5 SD] \\
\hline \multirow[t]{2}{*}{ INV therapy } & 4/11 (36) & $8 / 20(40)$ & $0 / 9(0)$ \\
\hline & [4 SD] & {$[1 \mathrm{CR}, 7 \mathrm{SD}]$} & \\
\hline
\end{tabular}

*Disease assessment was based on radiographic review by independent radiologists and review of clinical data by independent oncologists; evaluable patients were those with tumor assessment available.

$\mathrm{MIPI}=$ Mantle Cell Lymphoma International Prognostic Index; PR = partial response; $\mathrm{SD}=$ stable disease $\geq 8$ weeks; $\mathrm{CR}=$ complete response; INV = Investigator's choice.
Table 3 Treatment duration in each treatment arm by simplified MIPI risk category $[13,14]$

\begin{tabular}{llll}
\hline Treatment & Low risk & Intermediate risk & High risk \\
\hline Temsirolimus 175/75 $\mathbf{~ m g}$ & & & \\
$\mathrm{n}$ & 14 & 24 & 16 \\
$\quad \begin{array}{l}\text { Mean (std dev), weeks } \\
\text { Temsirolimus 175/25 mg }\end{array}$ & $32.4(22.0)$ & $21.1(24.8)$ & $10.5(8.8)$ \\
$\mathrm{n}$ & 15 & 18 & \\
Mean (std dev), weeks & $39.0(42.3)$ & $17.6(11.4)$ & $11.7(12.4)$ \\
INV therapy & & & \\
$\mathrm{n}$ & 21 & 21 & 11 \\
Mean (std dev), weeks & $8.1(7.8)$ & $9.8(10.3)$ & $3.3(2.4)$ \\
\hline
\end{tabular}

MIPI = Mantle Cell Lymphoma International Prognostic Index; std dev = standard deviation; INV = Investigator's choice.

PFS was 3.6 months longer than in the INV group, but this difference was not statistically significant. Similar median PFS were observed for the different patient cohorts (exclusion of patients with blastoid variant, exclusion of patients with missing MIPI values, and exclusion of patients with both blastoid variant and/or at least one missing MIPI value) compared with the analysis of all patients, except for the longer PFS observed in low-risk patients after patients with missing MIPI values were excluded (Table 4). A possible explanation for the longer PFS found after patients with missing MIPI values were excluded from the low-risk group is that this low-risk group might include patients that should have probably been assigned a higher risk level if all MIPI values were recorded for them. By excluding patients with missing MIPI values from this low-risk group, the true value of temsirolimus 175/75 mg becomes more evident.

Mean overall survival (OS) in patients treated with temsirolimus $175 / 75 \mathrm{mg}$ was 18.0 months in low-risk, 12.8 months in intermediate-risk, and 5.3 months in highrisk groups (Table 4). Though not statistically significant, a 7.5 month improvement in median OS was observed in low-risk patients with temsirolimus $175 / 75 \mathrm{mg}$ compared with INV (18.0 vs 10.5 months; $P=0.069$ ). Similar OS results observed for the different patient cohorts with excluded patients (Table 4).

\section{Safety}

For all treatment groups, low-risk patients had longer durations of exposure than did high-risk patients (Table 3). In both temsirolimus arms, the mean duration of treatment by MIPI risk category was: Low $>$ Intermediate $>$ High. For the INV arm, mean treatment durations were Low $\approx$ Intermediate $>$ High (Table 3).

Among patients treated with temsirolimus 175/75 mg, grade 3 or 4 thrombocytopenia or infection appeared to occur less frequently in low-risk patients than in highrisk patients; no incidence pattern was noted for grade 3 


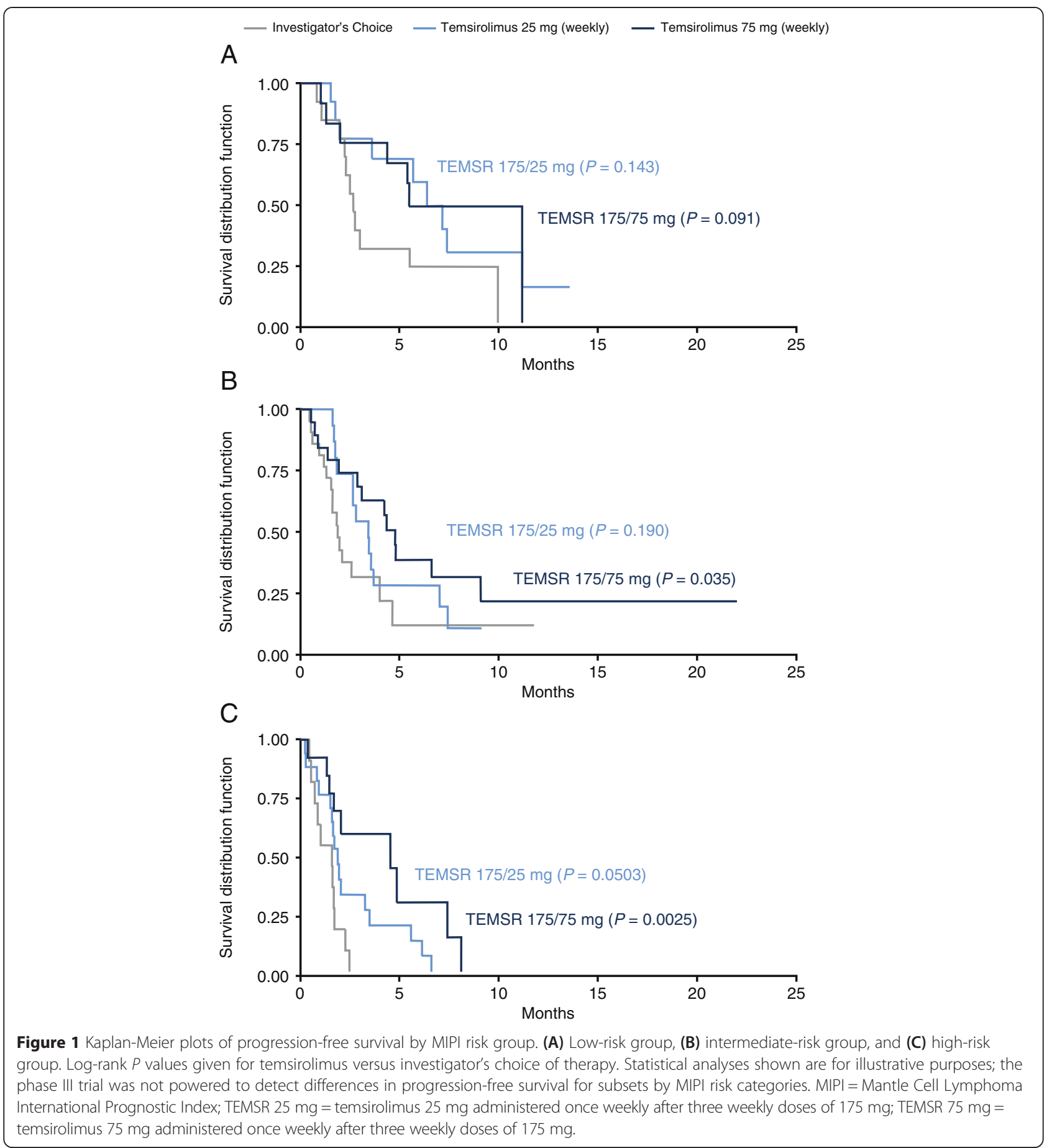

or 4 anemia by risk group. The numbers of patients with at least one dose delay by simplified MIPI risk category are provided online in Additional file 1: Table S1.

\section{Prognostic factors in relapsed/refractory MCL}

For newly diagnosed patients, MIPI classification is increasingly incorporated in clinical trial designs for stratification, as well as in clinical practice to inform treatment decisions [16]. Although not formally established, secondary MIPI in relapse is now frequently used in trials of relapsed/refractory MCL [13,14,17].

In our analysis, secondary MIPI classification, which was calculated for patients with relapsed/refractory MCL, revealed the potential for robust prognostic separation within our randomized phase III trial, although data were not available for all patients [9]. MIPI scores were observed to 
Table 4 Progression-free survival by MIPI risk category and by analyzed cohort

\begin{tabular}{|c|c|c|c|c|c|c|}
\hline \multirow[t]{2}{*}{ Patient cohort } & \multicolumn{3}{|c|}{ Median PFS $(95 \% \mathrm{Cl})$, months } & \multicolumn{3}{|c|}{ Median OS $(95 \% \mathrm{Cl})$, months } \\
\hline & $\begin{array}{l}\text { Temsirolimus } \\
175 / 75 \mathrm{mg}\end{array}$ & $\begin{array}{l}\text { Temsirolimus } \\
175 / 25 \mathrm{mg}\end{array}$ & INV therapy & $\begin{array}{l}\text { Temsirolimus } \\
175 / 75 \mathrm{mg}\end{array}$ & $\begin{array}{l}\text { Temsirolimus } \\
175 / 25 \mathrm{mg}\end{array}$ & INV therapy \\
\hline \multicolumn{7}{|l|}{ Low risk } \\
\hline \multirow[t]{2}{*}{ All } & $n=14$ & $\mathrm{n}=15$ & $n=22$ & $n=14$ & $n=15$ & $n=22$ \\
\hline & $5.3(4.2,10.9)$ & $6.2(3.5,10.9)$ & $2.6(2.1,5.4)$ & $18.0(11.1,22.3)$ & $14.5(11.0, \mathrm{NA})$ & $10.5(6.7,16.6)$ \\
\hline \multirow[t]{2}{*}{ Blastoid excluded } & $n=14$ & $n=15$ & $n=22$ & $n=14$ & $n=15$ & $n=22$ \\
\hline & $5.3(4.2,10.9)$ & $6.2(3.5,10.9)$ & $2.6(2.1,5.4)$ & $18.0(11.1,22.3)$ & $14.5(11.0, \mathrm{NA})$ & $10.5(6.7,16.6)$ \\
\hline \multirow[t]{2}{*}{ Missing values for MIPI excluded } & $n=12$ & $n=13$ & $n=16$ & $n=12$ & $n=13$ & $n=16$ \\
\hline & $10.9(4.2,10.9)$ & $6.2(1.9,10.9)$ & $2.9(2.4,9.7)$ & $18.0^{*}(14.1,22.3)$ & $14.5(11.0, \mathrm{NA})$ & $9.5(5.3,16.6)$ \\
\hline \multirow[t]{2}{*}{ Blastoid and missing values excluded } & $n=12$ & $n=13$ & $n=16$ & $n=12$ & $n=13$ & $n=16$ \\
\hline & $10.9(4.2,10.9)$ & $6.2(1.9,10.9)$ & $2.9(2.4,9.7)$ & $18.0^{*}(14.1,22.3)$ & $14.5(11.0, \mathrm{NA})$ & $9.5(5.3,16.6)$ \\
\hline \multicolumn{7}{|l|}{ Intermediate risk } \\
\hline \multirow[t]{2}{*}{ All } & $n=24$ & $\mathrm{n}=18$ & $n=21$ & $n=24$ & $\mathrm{n}=18$ & $n=21$ \\
\hline & $4.3^{*}(2.9,9.1)$ & $3.4(2.6,3.7)$ & $1.9(1.6,4.0)$ & $12.8(8.1, \mathrm{NE})$ & $8.8(8.1,20.6)$ & $12.4(5.7,15.1)$ \\
\hline \multirow[t]{2}{*}{ Blastoid excluded } & $n=24$ & $n=16$ & $\mathrm{n}=19$ & $n=24$ & $n=16$ & $n=19$ \\
\hline & $4.3(2.9,9.1)$ & $3.4(1.8,7.0)$ & $1.9(1.6,4.0)$ & $12.8(8.1, N A)$ & $8.8(8.1,20.6)$ & $13.6(5.7, \mathrm{NA})$ \\
\hline \multirow[t]{2}{*}{ Missing values for MIPI excluded } & $n=22$ & $\mathrm{n}=18$ & $\mathrm{n}=19$ & $n=22$ & $\mathrm{n}=18$ & $\mathrm{n}=19$ \\
\hline & $4.8^{*}(3.1,9.1)$ & $3.4(2.6,3.7)$ & $1.9(1.3,4.0)$ & $14.3(10.0, N A)$ & $8.8(8.1,20.6)$ & $12.4(5.7,15.1)$ \\
\hline \multirow[t]{2}{*}{ Blastoid and missing values excluded } & $n=22$ & $n=16$ & $n=17$ & $n=22$ & $n=16$ & $\mathrm{n}=17$ \\
\hline & $4.8^{*}(3.1,9.1)$ & $3.4(1.8,7.0)$ & $1.9(1.3,4.6)$ & $14.3(10.0, N A)$ & $8.8(8.1,20.6)$ & $12.4(5.7, \mathrm{NA})$ \\
\hline \multicolumn{7}{|l|}{ High risk } \\
\hline \multirow[t]{2}{*}{ All } & $n=16$ & $n=21$ & $n=11$ & $n=16$ & $n=21$ & $n=11$ \\
\hline & $4.5^{\dagger}(1.7,7.4)$ & $1.9(1.5,3.3)$ & $1.6(0.7,1.7)$ & $5.3(2.0,9.9)$ & $4.1(2.0,7.2)$ & $3.5(2.0,4.8)$ \\
\hline \multirow[t]{2}{*}{ Blastoid excluded } & $n=16$ & $n=14$ & $n=9$ & $n=16$ & $\mathrm{n}=14$ & $n=9$ \\
\hline & $4.5^{\ddagger}(1.7,7.4)$ & $1.9^{*}(1.7,5.6)$ & $1.6(0.9,1.7)$ & $5.3(2.0,9.9)$ & $5.1(3.3,14.6)$ & $3.7(3.2,20.4)$ \\
\hline \multirow[t]{2}{*}{ Missing values for MIPI excluded } & $n=16$ & $\mathrm{n}=18$ & $n=11$ & $n=16$ & $\mathrm{n}=18$ & $n=11$ \\
\hline & $4.5^{\dagger}(1.7,7.4)$ & $1.9^{*}(1.5,3.3)$ & $1.6(0.7,1.7)$ & $5.3(2.0,9.9)$ & $4.5(3.3,7.2)$ & $3.5(2.0,4.8)$ \\
\hline \multirow[t]{2}{*}{ Blastoid and missing values excluded } & $n=16$ & $n=12$ & $n=9$ & $n=16$ & $\mathrm{n}=12$ & $n=9$ \\
\hline & $4.5^{\ddagger}(1.7,7.4)$ & $1.9^{*}(1.7,5.6)$ & $1.6(0.9,1.7)$ & $5.3(2.0,9.9)$ & $5.1(3.3,14.6)$ & $3.7(3.2,20.4)$ \\
\hline
\end{tabular}

${ }^{{ }^{P} P<0.05 \text { versus INV. }}$

${ }^{\dagger} P<0.005$ versus INV.

${ }^{\ddagger} P<0.01$ versus INV.

$\mathrm{MIPI}=$ Mantle Cell Lymphoma International Prognostic Index; PFS = progression-free survival; $\mathrm{Cl}=$ confidence interval; OS = overall survival; INV = Investigator's choice of therapy.

be good predictors of OS in all three treatment groups in the current study. There was a clear superiority of treatment efficacy in patients with low- and intermediate-risk MIPI categories, whereas patients in the high-risk category did not show improved OS with any of the treatments. Thus, MIPI scores may be applicable for prognostic evaluation and risk-adapted therapeutic strategies in these hardto-treat patients. Furthermore, including secondary MIPI classification in future trials may make the results from these trials more comparable.

The results of this study should be viewed against its limitations. First, this study was not designed to collect MIPI parameters, which resulted in missing MIPI values for some patients. Second, using the simplified MIPI classification to divide patients into the different risk categories resulted in a lower number of patients available for efficacy evaluation in each arm, thus limiting the statistical power of many of these comparisons.

\section{Conclusions}

In conclusion, temsirolimus induced responses in all risk groups of patients with relapsed/refractory MCL who were retrospectively assigned MIPI scores. In all MIPI risk groups, objective response rates and CBRs were higher in patients treated with temsirolimus $175 / 75 \mathrm{mg}$ compared with INV. Trends toward improvements in PFS and OS were also observed in all risk groups of patients treated with temsirolimus $175 / 75 \mathrm{mg}$ versus INV. 
In all three treatment groups, patients with high risk had dismal outcomes, suggesting that MIPI classification may have value as a stratification factor for future clinical trials in relapsed and/or refractory, as well as newly diagnosed, MCL populations. Overall, this analysis indicates that earlier use of temsirolimus, when patients have favorable (low) secondary MIPI, may help to optimize its benefit.

\section{Design and methods \\ Patients and study design}

This post hoc, retrospective subset analysis utilized data from a global phase III clinical trial (ClinicalTrials.gov, NCT00117598) in which patients with relapsed or refractory MCL were randomized to receive temsirolimus 175/ $75 \mathrm{mg}$, temsirolimus $175 / 25 \mathrm{mg}$ or INV. Patient recruitment and trial design were previously described [9]. This trial enrolled patients from June 2005 through July 2007. Local institutional review boards at all participating centers approved the study protocol. Participating patients provided written informed consent at the time of enrollment to permit various data analyses, including exploratory subset analyses.

\section{Prognostic classification}

Simplified MIPI is based on four independent prognostic factors: age, Eastern Cooperative Oncology Group (ECOG) performance status, lactate dehydrogenase level and white blood cell count $[13,14,17]$. Performance status was collected in the database as KPS; for MIPI scoring, KPS was converted to ECOG performance status as: KPS $\geq 80=$ ECOG 1 (0 MIPI points); KPS $<80=$ ECOG 2 ( 2 MIPI points). Characteristics of patients recorded at the time of enrollment were used to generate simplified MIPI scores and to classify patients as low, intermediate or high risk at baseline. Data were missing in some cases, resulting in a lower number of patients available for comparison. In an extensive analysis, we either excluded patients with blastoid variant, patients with missing MIPI values or patients with both blastoid variant and/or at least one missing MIPI value, or included all patients. When all patients were included, the MIPI point value for a particular missing parameter was handled as a zero. Due to the retrospective nature of this analysis, we limited the analysis to the independent assessment.

\section{Statistical methods}

Median PFS and OS were calculated using Kaplan-Meier estimates. Significance of the treatment effect between two treatment groups is indicated by log-rank $P$ values $\leq 0.05$. The HR was calculated using a Cox proportional hazards model. Statistical analyses shown are for explanatory purposes, as the phase III trial was not powered to detect differences in outcomes by MIPI.

\section{Additional file}

Additional file 1: Table S1. Number of patients with at least one dose delay, by simplified MIPI risk category. Number and percent of patients who had at least one dose delay by simplified MIPI risk category and by treatment arm.

\section{Abbreviations}

CBR: Clinical benefit rate; Cl: Confidence interval; CR: Complete response; ECOG: Eastern Cooperative Oncology Group; HR: Hazard ratio; INV: Investigator's choice of therapy; KPS: Karnofsky performance status; MCL: Mantle cell lymphoma; MIPI: Mantle Cell Lymphoma International Prognostic Index; OS: Overall survival; PFS: Progression-free survival; PR: Partial response; SD: Stable disease; Std dev: Standard deviation.

\section{Competing interests}

G. Hess has served as a remunerated consultant for Pfizer Inc. He also has received honoraria and research funding from Pfizer Inc. B. Coiffier has served on a speaker's bureau for Pfizer Inc. M. Crump and J. Romaguera declare that they have no competing conflicts. C. Gisselbrecht and F. Offner have received research funding from Pfizer Inc. L. Kang was a paid consultant for Pfizer Inc at the time of this study. P. Moran was an employee of Pfizer Inc when the manuscript was drafted. No author received an honorarium or other form of financial support related to the development of this manuscript.

\section{Authors' contributions}

Study design: GH, LK, PM. Principal investigator: GH. Study investigator: GH, BC, MC, CG, FO, JR. Patient enrollment: GH, BC, MC, CG, FO, JR. Collection and assembly of data: GH, BC, MC, CG, FO, JR, LK, PM. Data analysis and interpretation: GH, BC, MC, CG, FO, JR, LK, PM. Manuscript preparation: GH, BC, MC, CG, FO, JR, LK, PM. Manuscript review and revisions: GH, BC, MC, CG, FO, JR, LK, PM. All authors read and approved the final manuscript.

\section{Acknowledgements}

This work was supported by Pfizer Inc. The original phase III trial was supported by Wyeth, which was acquired by Pfizer in October 2009. Medical writing and editorial support was provided by Christine $\mathrm{H}$. Blood, PhD, of Peloton Advantage and Vardit Dror, PhD, of Engage Scientific Solutions and was funded by Pfizer Inc.

\section{Author details}

'Department of Hematology/Oncology, Johannes Gutenberg University, Langenbeckstr. 1, Mainz DE 55101, Germany. ${ }^{2}$ Centre Hospitalier Lyon Sud, Hospices Civils de Lyon, Pierre-Benite, France. ${ }^{3}$ Princess Margaret Hospital, Toronto, ON, Canada. ${ }^{4}$ Hôpital Saint-Louis, Paris, France. ${ }^{5}$ Ghent University Hospital, Ghent, Belgium. ${ }^{6}$ The University of Texas MD Anderson Cancer Center, Houston, TX, USA. ${ }^{7}$ Pfizer Inc, Cambridge, MA, USA. ${ }^{8}$ Prizer Inc, Dublin, Ireland.

Received: 21 January 2015 Accepted: 18 March 2015

Published online: 11 April 2015

\section{References}

1. Chandran R, Gardiner SK, Simon M, Spurgeon SE. Survival trends in mantle cell lymphoma in the United States over 16 years 1992-2007. Leuk Lymphoma. 2012;53:1488-93.

2. Dietrich S, Tielesch B, Rieger M, Nickelsen M, Pott C, Witzens-Harig M, et al. Patterns and outcome of relapse after autologous stem cell transplantation for mantle cell lymphoma. Cancer. 2011;117:1901-10.

3. Dreyling M, Kluin-Nelemans HC, Bea S, Klapper W, Vogt N, Delfau-Larue MH, et al. Update on the molecular pathogenesis and clinical treatment of mantle cell lymphoma: report of the 11th annual conference of the European mantle cell lymphoma network. Leuk Lymphoma. 2013;54:699-707.

4. Herrmann A, Hoster E, Zwingers T, Brittinger G, Engelhard M, Meusers P, et al. Improvement of overall survival in advanced stage mantle cell Iymphoma. J Clin Oncol. 2009;27:511-8.

5. Argyriou P, Economopoulou P, Papageorgiou S. The role of mTOR inhibitors for the treatment of B-cell lymphomas. Adv Hematol. 2012;2012:435342. 
6. Coiffier B, Ribrag V. Exploring mammalian target of rapamycin (mTOR) inhibition for treatment of mantle cell lymphoma and other hematologic malignancies. Leuk Lymphoma. 2009;50:1916-30

7. Perez-Galan P, Dreyling M, Wiestner A. Mantle cell lymphoma: biology, pathogenesis, and the molecular basis of treatment in the genomic era. Blood. 2011;117:26-38.

8. Ansell SM, Inwards DJ, Rowland Jr KM, Flynn PJ, Morton RF, Moore Jr DF, et al. Low-dose, single-agent temsirolimus for relapsed mantle cell lymphoma: a phase 2 trial in the North central cancer treatment group. Cancer. 2008;113:508-14.

9. Hess G, Herbrecht R, Romaguera J, Verhoef G, Crump M, Gisselbrecht C, et al. Phase III study to evaluate temsirolimus compared with investigator's choice therapy for the treatment of relapsed or refractory mantle cell lymphoma. J Clin Oncol. 2009;27:3822-9.

10. Witzig TE, Geyer SM, Ghobrial I, Inwards DJ, Fonseca R, Kurtin P, et al. Phase II trial of single-agent temsirolimus (CCl-779) for relapsed mantle cell lymphoma. J Clin Oncol. 2005;23:5347-56.

11. Fujiwara Y, Kiyota N, Chayahara N, Suzuki A, Umeyama Y, Mukohara T, et al. Management of axitinib (AG-013736)-induced fatigue and thyroid dysfunction, and predictive biomarkers of axitinib exposure: results from phase I studies in Japanese patients. Invest New Drugs. 2011;30:1055-64.

12. Dreyling M, Thieblemont C, Gallamini A, Arcaini L, Campo E, Hermine O, et al. ESMO Consensus conferences: guidelines on malignant lymphoma. part 2: marginal zone lymphoma, mantle cell lymphoma, peripheral T-cell lymphoma. Ann Oncol. 2013;24:857-77.

13. Geisler CH, Kolstad A, Laurell A, Raty R, Jerkeman M, Eriksson M, et al. The Mantle Cell Lymphoma International Prognostic Index (MIPI) is superior to the International Prognostic Index (IPI) in predicting survival following intensive first-line immunochemotherapy and autologous stem cell transplantation (ASCT). Blood. 2010;115:1530-3.

14. Hoster E, Dreyling M, Klapper W, Gisselbrecht C, van Hoof A, Kluin-Nelemans $\mathrm{HC}$, et al. A new prognostic index (MIPI) for patients with advanced-stage mantle cell lymphoma. Blood. 2008;111:558-65.

15. Todorovic M, Balint B, Andjelic B, Stanisavljevic D, Kurtovic NK, Radisavljevic $Z$, et al. Outcome prediction of advanced mantle cell lymphoma by international prognostic index versus different mantle cell lymphoma indexes: one institution study. Med Oncol. 2012;29:2212-9.

16. Vose JM. Mantle cell lymphoma: 2012 update on diagnosis, risk-stratification, and clinical management. Am J Hematol. 2012;87:604-9.

17. Wang ML, Rule S, Martin P, Goy A, Auer R, Kahl BS, et al. Targeting BTK with ibrutinib in relapsed or refractory mantle-cell lymphoma. N Engl J Med. 2013;369:507-16

\section{Submit your next manuscript to BioMed Central and take full advantage of:}

- Convenient online submission

- Thorough peer review

- No space constraints or color figure charges

- Immediate publication on acceptance

- Inclusion in PubMed, CAS, Scopus and Google Scholar

- Research which is freely available for redistribution 